\title{
Evaluation of membranes for use in on-line cell separation during mammalian cell perfusion processes
}

\author{
Heino Büntemeyer, Christoph Böhme and Jürgen Lehmann \\ Institute for Cell Culture Technology, University of Bielefeld, P.O. Box 100131, 33501 Bielefeld, Germany
}

Key words: Hybridomate, monoclonal antibody, perfusion, microfiltration, membrane, fouling

\begin{abstract}
In this study two microporous hollow fibre membranes were evaluated for their use as cell retention device in continuous perfusion systems. A chemically modified permanent hydrophillic PTFE membrane and a hydrophilized PP membrane were tested. To investigate the filtration characteristic under process conditions each membrane was tested during a long term perfusion cultivation of a hybridoma cell line. In both cultivations the conditions influencing membrane filtration (e.g. transmembrane flux) were kept constant. Filtration behaviour was investigated by monitoring transmembrane pressure and protein permeability. Transmembrane pressure was measured on-line with an autoclavable piezo-resistive pressure sensor. Protein permeability was determined by quantitative evaluation of unreduced, Coomassie stained SDS-PAGE. The membrane fouling process influences the filtration characteristic of both membranes in a different way. After fermentation the PP membrane was blocked by a thick gel layer located in the big outer pores of the asymmetric membrane structure. The hydraulic resistance was higher but the protein permeability was slightly better than of the PTFE membrane. For this reason the PP membrane should be preferred. On the other hand, transmembrane pressure decreases slower when the PTFE membrane is used, which favours this membrane for long term cultivations, especially when low molecular weight proteins $(<30 \mathrm{KD})$ are produced.
\end{abstract}

Abbreviations: PP - Polypropylene; PTFE - Polytetrafluoroethylene

\section{Introduction}

For the cultivation of mammalian cells and the production of biopharmaceuticals (recombinant proteins, monoclonal antibodies) a wide variety of bioreactor systems were developed. Because of the low growth rate and high nutrient demands of mammalian cells continuous systems are often used. To obtain high cell densities cell retention devices have been employed. These devices can be placed into the bioreactor or in an external loop. As internal systems spin filters (rotating sieves) (Fenge et al., 1993) and membrane devices proved to be successful (Büntemeyer et al., 1987). Synthetic membranes can be used as hollow fibres or flat membranes in an arrangement of static or cross flow elements.
The main problems using membranes in static or cross flow mode occur from fouling processes which affect transmembrane flow rate and filtration characteristic. Synthetic membranes in bioreactors used for cell retention are of microfiltration type with pore sizes of $0.1-5 \mu \mathrm{m}$. In most cases microporous membranes are used. Because of their special structure cells, cell debris and macromolecules (proteins, DNA, etc.) can attach to the membrane and cause the fouling. They fill the pores and form a layer which, in addition to the synthetic membrane, behaves as a secondary membrane (Le and Gollan 1989; Meireles et al., 1991). The hydraulic resistance rises. The secondary membrane, mainly consisting of a gel formed by the macromolecules, changes the filtration type from microfiltration to ultrafiltration. The active pore size decreases from micropores $(0.1-5 \mu)$ to nanopores $(1-20 \mathrm{~nm})$. 
At this stage a filtration phenomenon, the concentration polarization, plays a major role. Macromolecules are now retained by the secondary membrane and the filtrate concentration decreases whereas the concentration in front of the secondary membrane rises. When the saturation concentration of those substances is reached they precipitate to the gel layer and enlarge it further (Flaschel et al., 1983). The consequence is a significant increase in transmembrane pressure drop if the flux through the membrane is kept constant.

The PTFE membrane used in this study was a symmetric microporous membrane (pore size is the same on both sides) while the PP membrane was of asymmetric structure with the smallest pores on the inner surface.

The aim of this study was the evaluation of the two hollow fibre membranes for their use in continuous perfusion processes of mammalian cell cultivations. Transmembrane pressure drop and protein permeability are used as characteristic quantities.

\section{Materials and methods}

\section{Bioreactor}

The bioreactor system used in this study was a 2 litre bench scale perfusion system based on a modified BIOSTAT BF2 bioreactor (B. Braun Biotech International, Melsungen, Germany). The reactor was equipped with the double membrane stirrer on which aeration and perfusion membranes were fixed (Büntemeyer et al., 1987).

The bioreactor was aerated with a hydrophobic hollow fibre membrane $\left(3 \mathrm{ml}^{-1}=245 \mathrm{~cm}^{2} \mathrm{l}^{-1}\right.$ ) (Lehmann et al., 1988) connected to a 4-channel gas supply for air, $\mathrm{O}_{2}, \mathrm{~N}_{2}$ and $\mathrm{CO}_{2}$ controlled by a digital control unit (DCU, B. Braun International) depending on setpoints of $\mathrm{pO}_{2}$ and $\mathrm{pH}$. Temperature was set to $37^{\circ} \mathrm{C}$, stirrer speed to $35 \mathrm{rpm}, \mathrm{pH}$ to 7.2 and $\mathrm{pO}_{2}$ to $40 \%$ air saturation.

Furthermore, the stirrer was equipped with internal hollow fibre microfiltration membranes. For cell-free continuous medium exchange during perfusion two different hollow fibre membranes were tested (Table 1). In each case the same filtration area of approx. 377 $\mathrm{cm}^{2}$ membrane was mounted onto the stirrer. Because of the different outer surface area of both membranes, it was necessary to use $4 \mathrm{~m}$ of the PTFE membrane and $4.62 \mathrm{~m}$ of the PP membrane, respectively. The membranes were connected on one end via a peri-
Table 1. Summary of the characteristics of the PP and PTFE membranes studied in this investigation

\begin{tabular}{lll}
\hline & PP & PTFE \\
\hline Material & $\begin{array}{l}\text { Polypropylene } \\
\text { (Accurel) } \\
\text { hydrophilized } \\
\text { (with ethanol) }\end{array}$ & $\begin{array}{l}\text { Polytetrafluoroethylene } \\
\text { (PTFE), modified } \\
\text { permanent hydrophilic }\end{array}$ \\
$\begin{array}{l}0.3 \mu \mathrm{m} \\
\text { pore size }\end{array}$ & $3 \mu \mathrm{m}$ \\
wall thickness & $0.4 \mathrm{~mm}$ & $0.5 \mathrm{~mm}$ \\
specific surface & & \\
outside & $81.7 \mathrm{~cm}^{2} \mathrm{~m}^{-1}$ & $94.3 \mathrm{~cm}^{2} \mathrm{~m}^{-1}$ \\
inside & $56.5 \mathrm{~cm}^{2} \mathrm{~m}^{-1}$ & $62.8 \mathrm{~cm}^{2} \mathrm{~m}^{-1}$ \\
porosity & $75 \%$ & $40-80 \%$ \\
bubble point & $0.25 \mathrm{bar}^{\text {(in water) }}$ & $1.55 \mathrm{bar}$ \\
\hline
\end{tabular}

staltic pump (Watson-Marlow 501UR) to the medium reservoir vessel and on the other end via a second pump to the harvest vessel (Fig. 1). Both pumps were controlled by a level sensor and ran alternatingly in a special manner. First, the feeding pump fills the reactor with a transmembrane flux of $0.0751 \mathrm{~m}^{-2} \mathrm{~min}^{-1}$ until maximal level is reached. Then the harvesting pump withdraws the supernatant with a lower transmembrane flux of $0.0591 \mathrm{~m}^{-2} \mathrm{~min}^{-1}$ for a defined time interval ( $30 \mathrm{~min}$ ). Next, the reactor is filled again and the whole procedure is repeated (Büntemeyer $e t$ al., 1987). For the measurement of the pressure drop during the harvesting step a sterilizable, piezo-resistive pressure sensor (type 4045 A5, Kistler, Winterthur, Switzerland) was fitted into the harvesting stream very close to the bioreactor outlet (Fig. 1). Above feed and harvest flux were chosen to provoke a more rapid membrane fouling. Optimal flux values are described earlier (Büntemeyer et al., 1987). Additionally, a bleed stream was connected direct to the bioreactor to control cell density and maintain steady state conditions.

Cells

The cell line used in this study was the hybridoma HB 58 (ATCC). This cell is a rat mouse hybridoma which produces rat antibodies type $\mathrm{IgG}_{1}$, specific for mouse $\kappa$ light chain. Cell numbers were determined microscopically by trypan blue exclusion. 


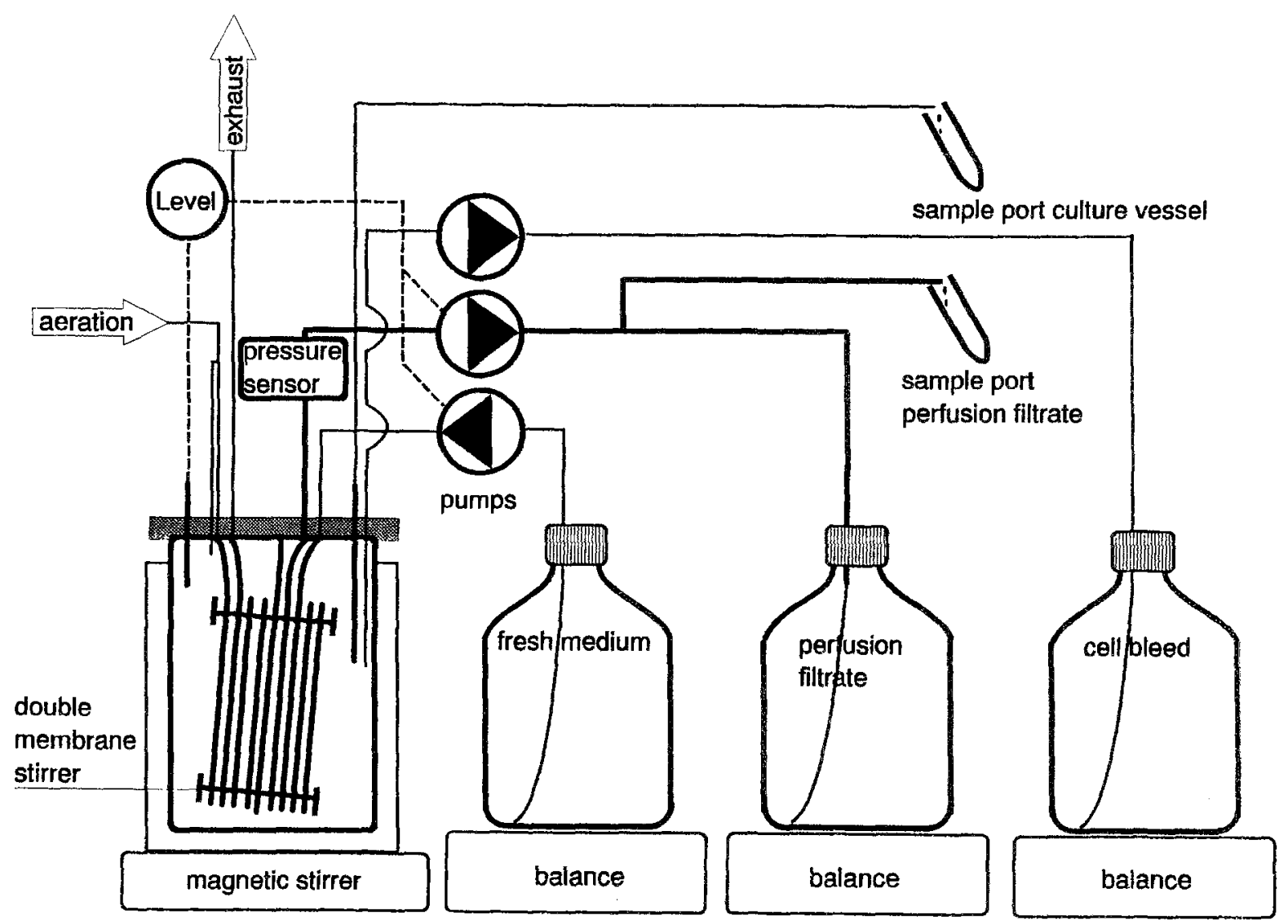

Fig. 1. Experimental setup of continuous perfusion system. A $2 \mathrm{~L}$ bench scale bioreactor was used. The double membrane stirrer was equipped with a hydrophobic PP membrane for aeration and the investigated membranes for perfusion.

\section{Medium}

The medium used for both experiments was a serumfree low protein medium (SF-medium) consisting of a 1:1 mixture of DMEM and F12 (Gibco, Eggenstein, Germany). The following supplements were used per litre medium: $10 \mathrm{mg}$ human transferrin (Fe saturated), $10 \mathrm{mg}$ bovine insulin, $50 \mu \mathrm{mol}$ ethanolamine and $2 \mathrm{ml}$ lipoprotein solution (ExCyte I, Bayer Diagnostics, München, Germany). To obtain high cell density in perfusion mode the serumfree medium was supplemented with glucose, sodium pyruvate and various concentrations of amino acids and glutamine accordingly to the demand of the cells in high cell density culture.

\section{Analytical methods}

Antibody concentrations in the supernatant were analyzed by a kinetic sandwich ELISA method (Enzyme:
Peroxidase; Substrate: o-Phenylenediamine) as described previously (Büntemeyer et al., 1991). For the determination of protein concentrations unreduced SDS-PAGE electrophoresis was done. The gels were stained with Coomassie Brilliant Blue using the Sensiquant method (Bülles et al., 1990). Quantitative evaluation of the gels was carried out by scanning with an Epson flat bed scanner GT6000 and analysing with Pharmacia's Gel Image software package 1DEVA. The quantitative results for antibody concentration obtained by gel scanning and ELISA were compared. They showed nearly the same accuracy and error margins. Comparable results for the other proteins should be expected. For optimal nutrient supply of the culture during perfusion concentrations of glucose and amino acids were analyzed by methods described previously (Büntemeyer et al., 1991). 


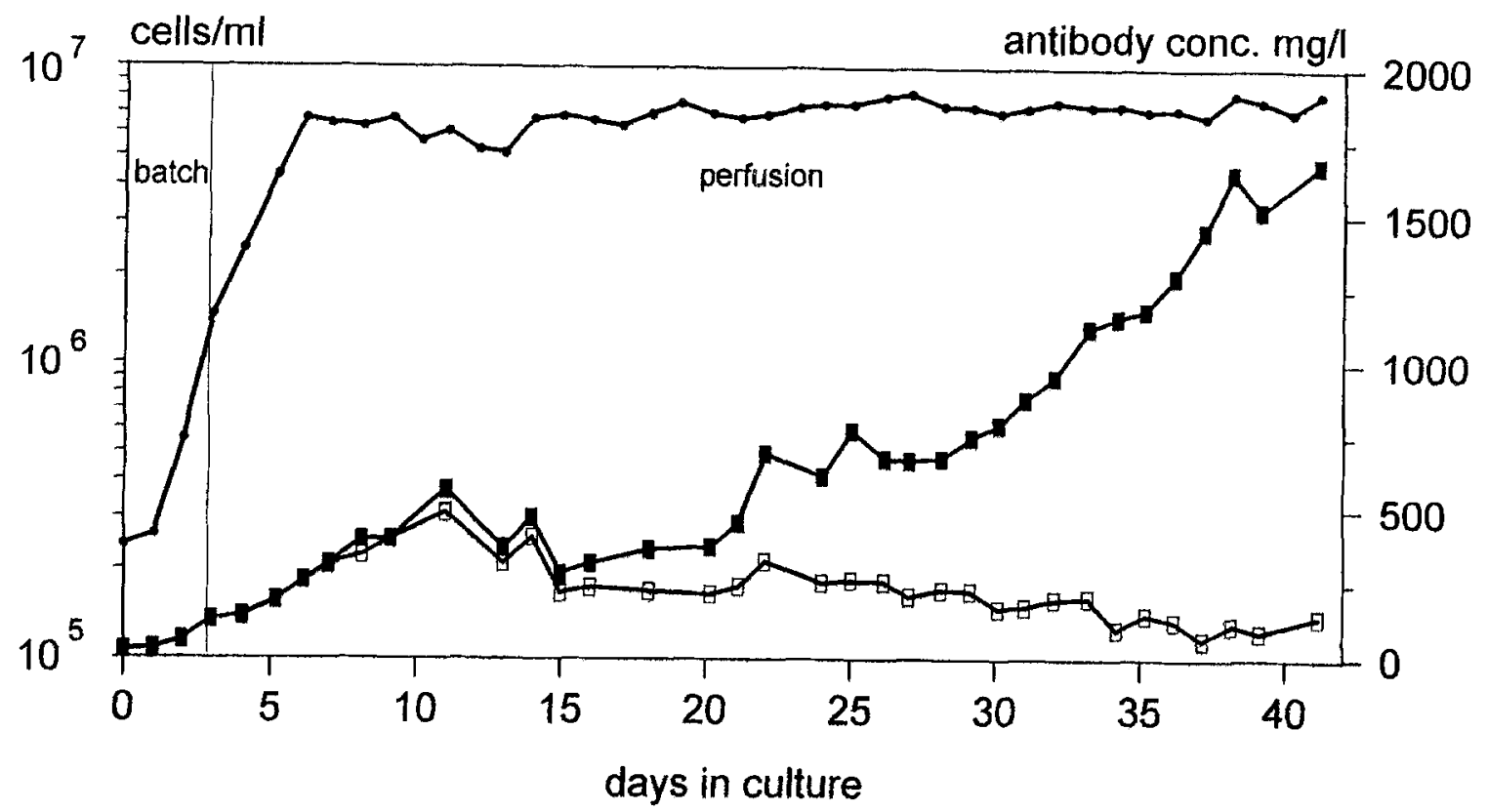

- viable cells \#-antibodies in culture vessel $\#$ antibodies in filtrate

Fig. 2. Time course of hybridoma cultivation in the $2 \mathrm{~L}$ perfusion system using the PP membrane. During perfusion phase viable cell density could be kept at a steady state concentration of approx. $7+10^{6} \mathrm{cells} \mathrm{ml}^{-1}$. From the antibody concentrations in the culture vessel and the perfusion filtrate the retainment by the mernbrane clearly can be șeen.

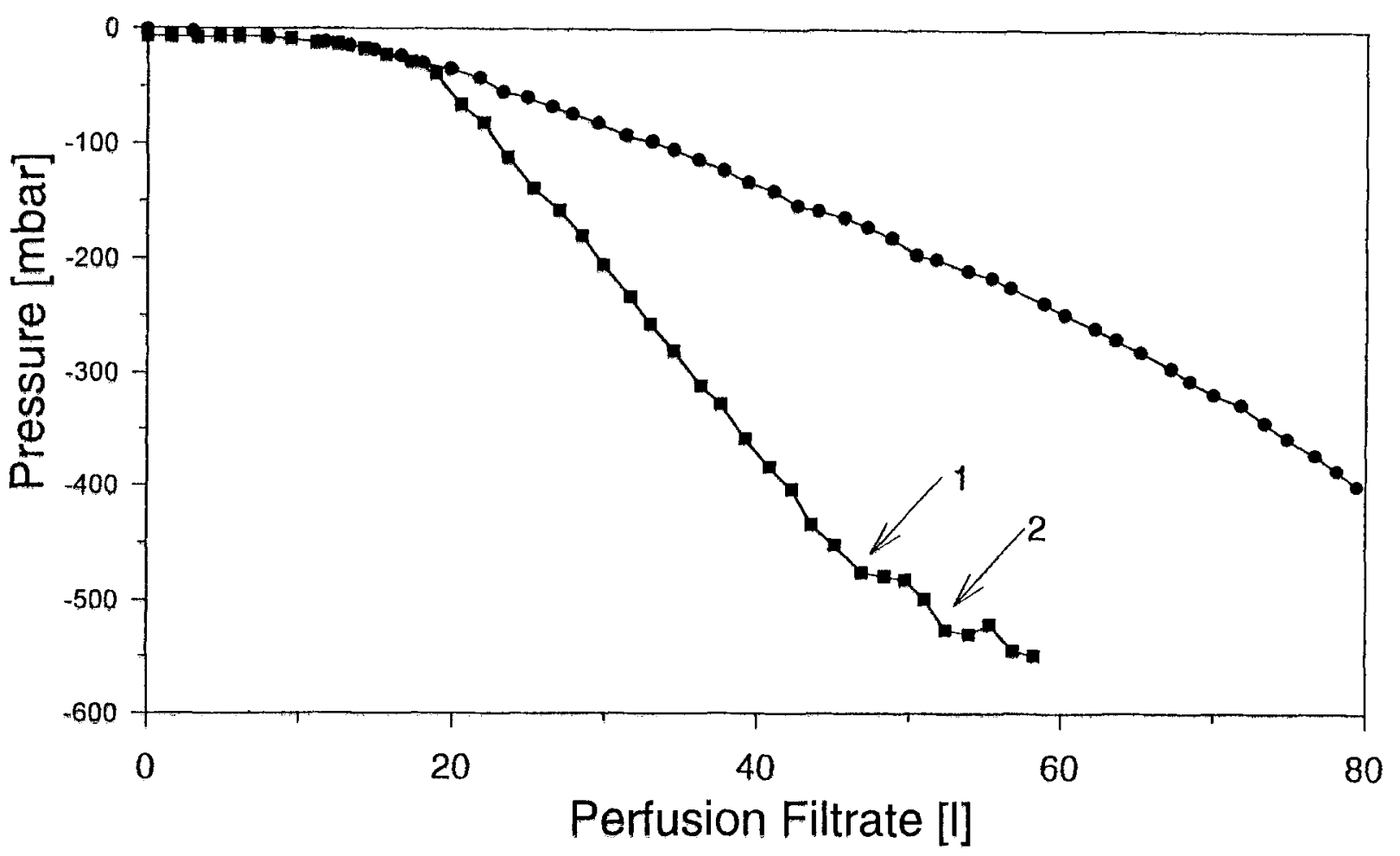

Fig. 3. Transmembrane pressure drop in the perfusion membranes during fermentation shown as function of filtrated volume. - - PP membrane, - - PTFE membrane. 1) lncrease of backflushing rate from $0.0751 \mathrm{~m}^{-2} \mathrm{~min}^{-1}$ to $0.151 \mathrm{~m}^{-2} \mathrm{~min}^{-1} ; 2$ ) further increase to $0.32 \mathrm{I}$ $\mathrm{m}^{-2} \mathrm{~min}^{-1}$ 


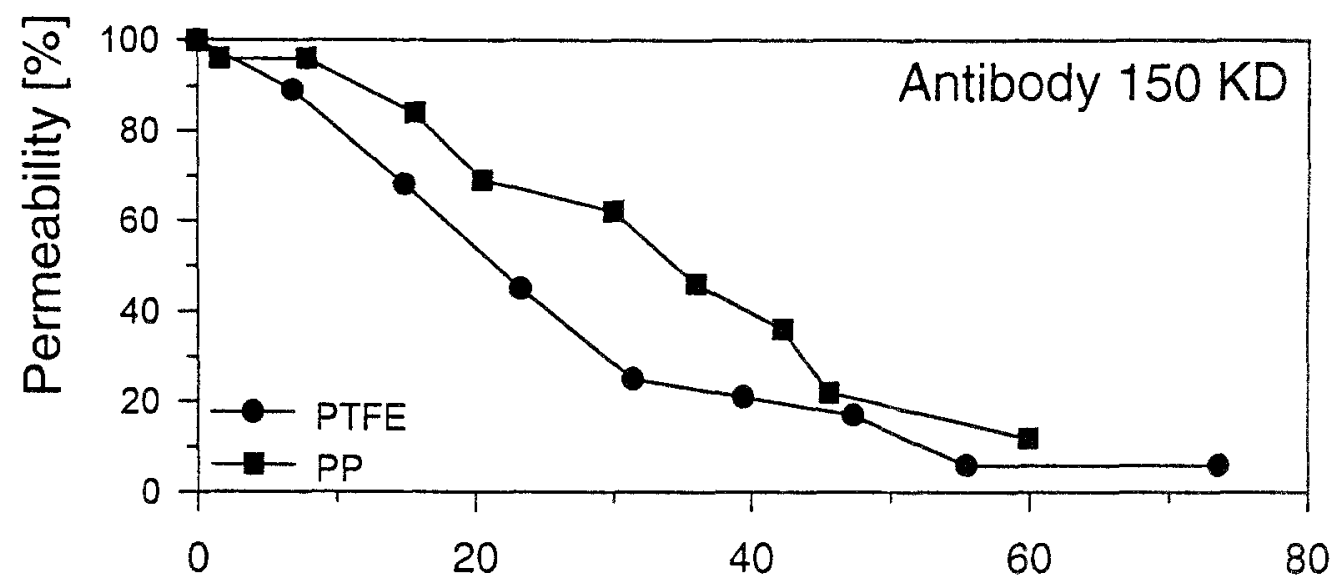

Filtrate [l]

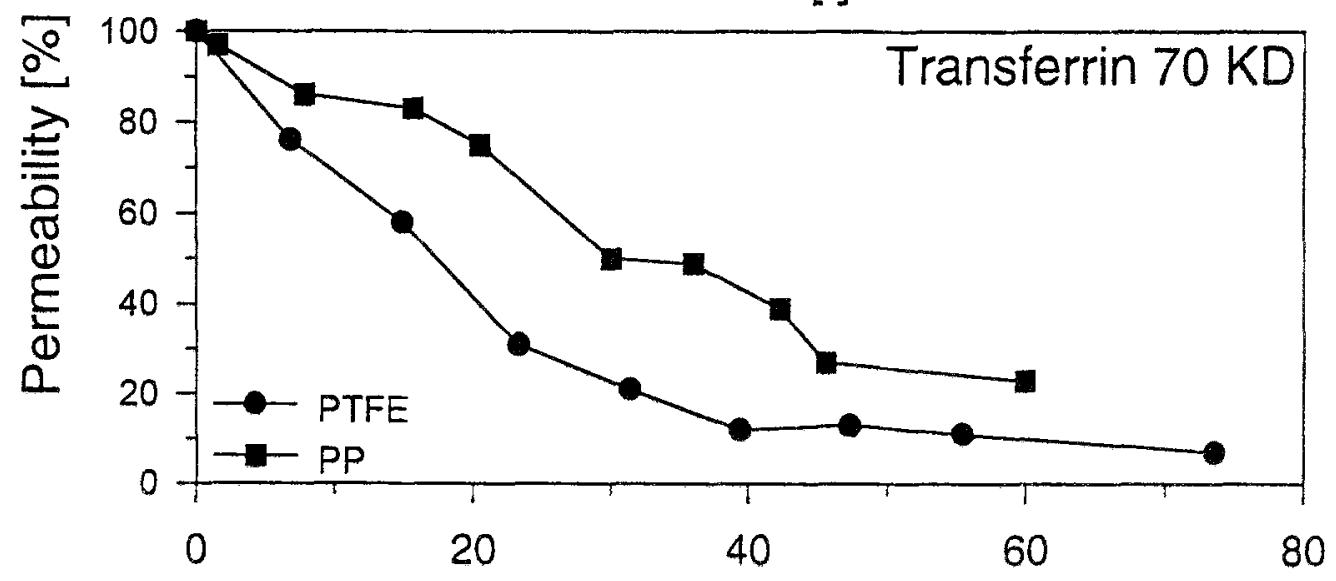

Filtrate [l]

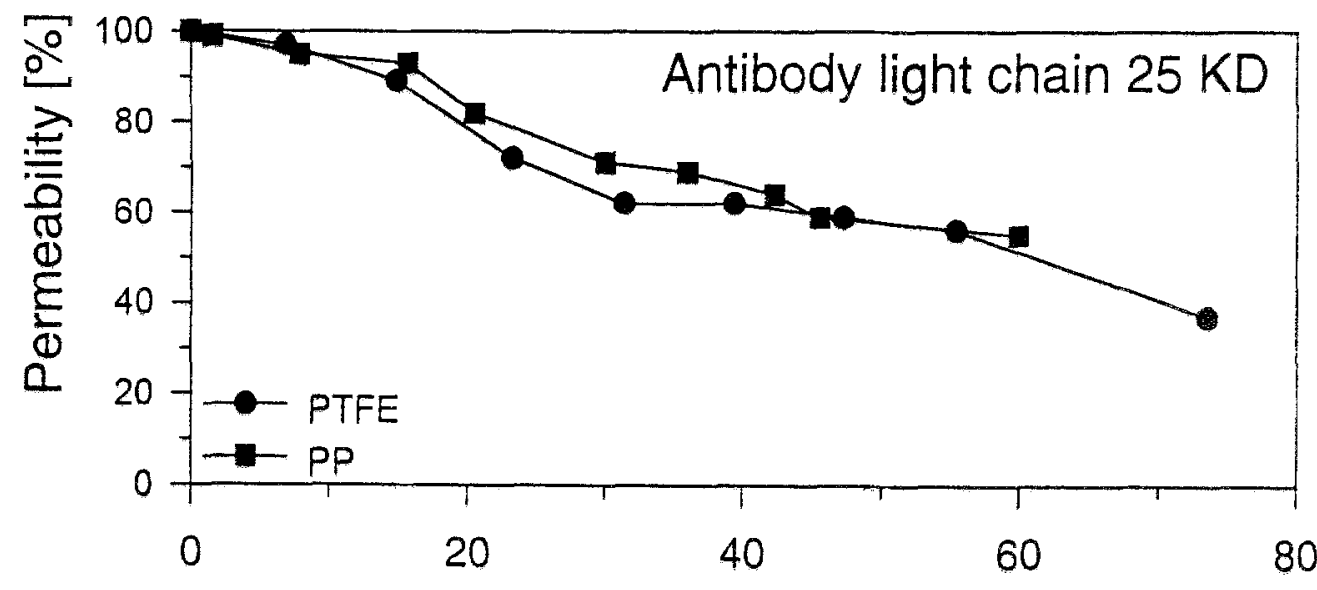

Filtrate [l]

Fig. 4. Protein permeability of the 3 major proteins in the hybridoma cultivations (antibody, transferrin, antibody light chain) shown as function of filtrated volume. The permeability is the percentage of the ratio of the concentration in the filtrate (permeate) and in the fermenter (concentrate) of each protein. 


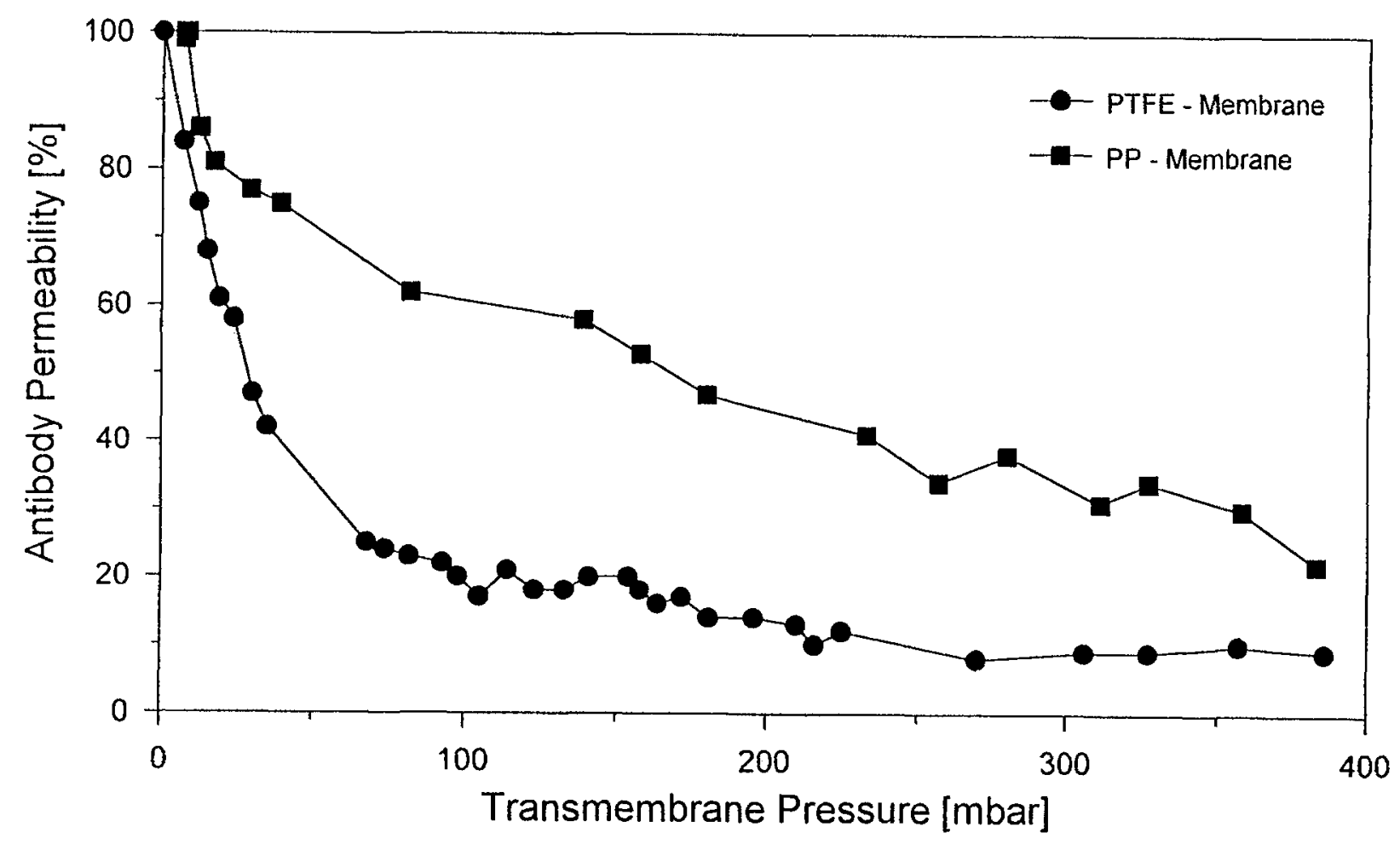

Fig. 5. Relation between antibody permeability and transmembrane pressure for both membranes.

\section{Results and discussion}

Two long term perfusion experiments were performed, one with each type of membrane. In Fig. 2 the time course of the cultivation with the PP membrane is shown. Cells were inoculated with a viable cell density of $2,4 \cdot 10^{5}$ cells $\mathrm{ml}^{-1}$. After a 3 days batch mode perfusion was activated with a rate of $D=0.8 \mathrm{~d}^{-1}$ and kept constant for the rest of the cultivation. Additionally, a cell bleed was activated with a rate of $D_{B}=0,2 d^{-1}$ at the same time. After day 8 a viable cell density of approx. $7 \cdot 10^{6}$ cells $\mathrm{ml}^{-1}$ was reached and could be maintained during the rest of the cultivation ( 35 days). The perfusion phase with cell bleed was performed under glucose limitation (data not shown) to maintain a stable steady state in respect to viable cell density. During perfusion antibody concentration was monitored in the bioreactor and the perfusion filtrate. From Fig. 2 it is obvious that, beginning with day 15 , antibody molecules were retained in the reactor, whereas the concentration in the perfusion filtrate decreased. The type of filtration changed from microfiltration to ultrafiltration. For this reason the antibody concentration reached a level of $1.6 \mathrm{~g} \mathrm{I}^{-1}$ at the end of the fermentation.
In the second cultivation the PTFE membrane was used (data not shown). This fermentation was performed in the same manner as the other cultivation. The same dilution rates (perfusion and cell bleed) and the same medium composition were used. Viable cell density reached approx. the same level of $7-8 \cdot 10^{6}$ cells $\mathrm{ml}^{-1}$. The change in filtration type was also observed.

Special attention during both cultivations was given to transmembrane pressure drop and protein permeability to investigate changes of filtration characteristic. The transmembrane pressure was monitored with a sterilizable piezoresistive pressure sensor which was fitted close to the membrane outlet (see Fig. 1). The pressure difference $\Delta p$ which is caused by the pump during harvesting phase was calculated from these data. In Fig. 3 the increase in pressure drop with increasing perfusion (=filtration) volume is depicted. The PTFE membrane shows a slower pressure increase than the PP membrane. Two attempts to decelerate pressure rise in the PP membrane by increasing the backflushing rate during filling step failed. The pressure rise could not be retarded significantly. Contrary to the findings concerning the pressure drop the PP membrane shows a better protein permeability for large molecules (see Fig. 4). For antibody and transferrin 


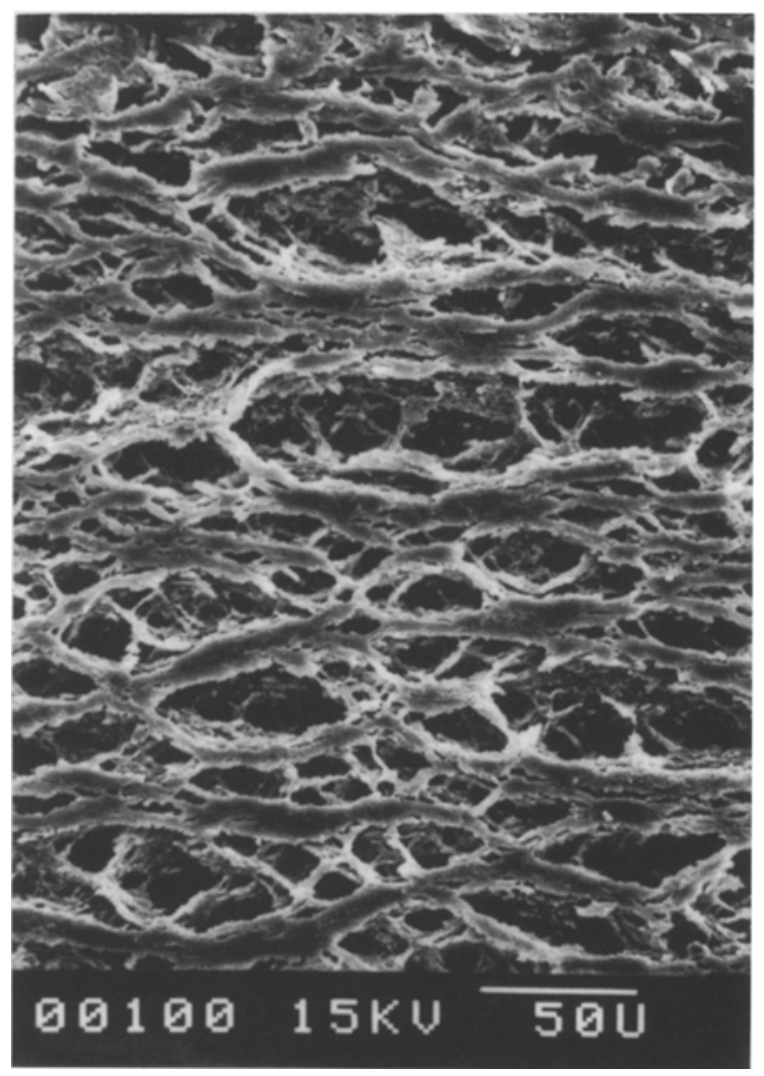

Fig. 6a) PP membrane, unused.

molecules the permeability of the PP membrane did not decrease with increasing filtration volume to such an extent as it occurred when the PTFE membrane was used. For smaller molecules like the antibody light chain the behaviour of both membranes is nearly the same. These findings lead to the conclusion that the fouling process has a different quality for each membrane. In case of the PP membrane fouling causes the formation of a gel layer with greater pores and higher hydrodynamic resistance. To solve thist apparent contradiction it is necessary to look at the filtration theory (Flaschel et al., 1983).

In the pore model ideal cylindric pores are assumed. According to Hagen-Poiseuille's law (1) the flux $\mathbf{J}$ is proportional to the transmembrane pressure drop $\Delta \mathbf{p}$. The hydraulic resistance $W(2)$ is dependent on the square of the pore diameter $\mathbf{d}$, the membrane porosity $\varepsilon$ and inverse proportional to the dynamic viscosity $\eta$ and the pore length $\mathbf{l}$. The total hydraulic resistance is a sum of the resistance of the synthetic membrane itself and the secondary membrane formed during fouling $\left(\mathrm{W}_{\text {total }}=\mathrm{W}_{\text {membrane }}+\mathrm{W}_{\text {layer }}\right)$.

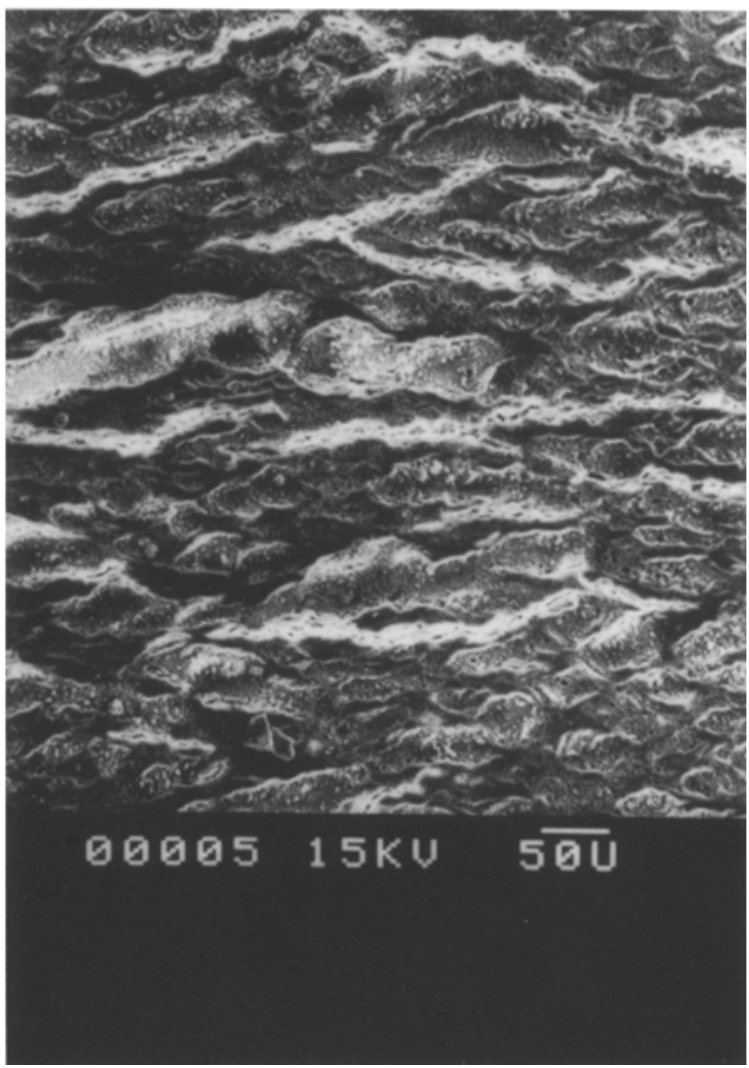

Fig. 6b) PP membrane after long term perfusion culture.

$$
\begin{aligned}
& J=\frac{1}{W} \cdot \Delta p \\
& \frac{1}{W} \sim \varepsilon \cdot \frac{d^{2}}{\eta \cdot l}
\end{aligned}
$$

It can be assumed that the resistance of the synthetic membrane is constant during the whole process. But, the equations have to be applied also to the gel layer formed as the secondary membrane since the transmembrane pressure drop is mainly caused by it. It can be assumed that the porosity of the gel and the viscosity of the culture broth are of same quality in both experiments. Since the apparent pore diameter d (see Fig. 4) and transmembrane pressure drop $\Delta \mathbf{p}$ (see Fig. 3) of the gel layer on the PP membrane are higher, also the value of the pore length 1 must be higher under the given condition of a constant flux. A greater pore length also means a thicker gel layer. Therefore, the fouling process caused the formation of a substantial thicker gel layer on the PP membrane than on the PTFE membrane. Fig. 5 presents the relation- 


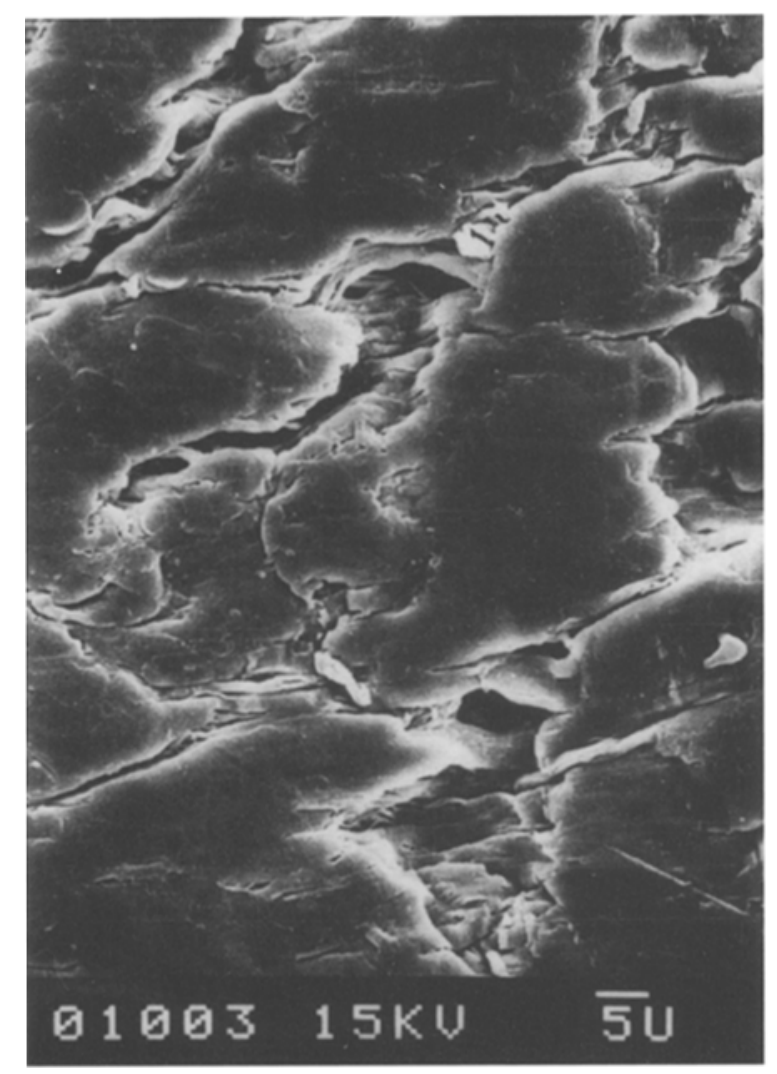

Fig. 6c) PTFE membrane, unused.

ship between transmembrane pressure and antibody permeability. In case of the PTFE membrane the antibody permeability already drops to about $20 \%$ when a transmembrane pressure of 100 mbar is reached. A permeability of $10 \%$ seems to be a stable situation even when the transmembrane pressure increases. For the PP membrane a decreased permeability of $20 \%$ is reached at $400 \mathrm{mbar}$, at the earliest. A further increase of transmembrane pressure will probably lower antibody permeability. The antibody permeability of the PP membrane is in any case about twice as high as the permeability of the PTFE membrane.

On the REM micrographs (Fig. 6a-d) the different structures of the membranes can be seen. The PTFE membrane has those pores, which are relevant for filtration, on the outer surface, while the PP membrane is very asymmetric with great pores on the outer surface and with the filtration pores on the inner surface. After the fermentation these large pores on the outer surface of the PP membrane are filled and blocked by the protein gel. That confirms the findings above which predict a longer pore length of the gel.

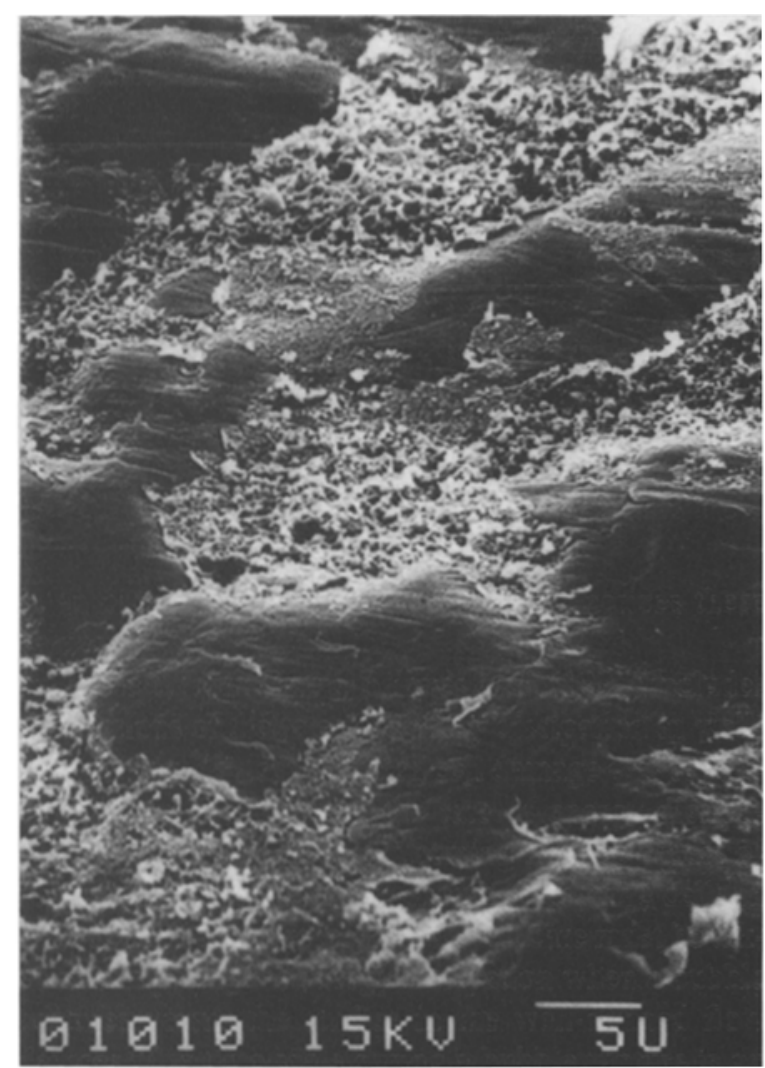

Fig. 6d) PTFE membrane after long term perfusion culture.

Figs. 6(a)-(6d). REM - micrographs of outer surfaces of both membranes used for microfiltration.

\section{Conclusion}

Both investigated microfiltration perfusion membranes can be used for internal cell retention if the correct filtration procedure is used. In both cases the filtration type changes during perfusion from microfiltration to ultrafiltration by forming a protein layer (Blasey, 1990; Blasey et al., 1991). The membrane fouling process influences the filtration characteristic of both membranes in a different way. The permeability of the PP membrane is slightly better than that of the PTFE membrane and therefore this type of membrane should be preferred. On the other hand, fouling cause a slower decrease of transmembrane pressure when the PTFE membrane is used, which favours this membrane for long term cultivations, especially when low molecular weight proteins $(<30 \mathrm{KD})$ are produced. 


\section{Acknowledgmenets}

We like to thank B. Braun International (Dr. C. Fenge) for providing the PTFE membranes and Dr. P. Heimann, Faculty of Biology, University of Bielefeld, for preparing the REM micrographs. This work was supported in part by the project 'Development of a procedure and a plant for the recirculation of nutrient media for animal cell culture' (BMFT ref No. 0319346A) of the German Ministry of Research.

\section{References}

Blasey HD (1990) Untersuchung zur Optimierung eines Perfusionsreaktorsystems für die Kultivierung von Animalzellen. Ph.D. Thesis, University of Hannover, Germany.

Blasey HD and Jäger V (1991) Strategies to increase the efficiency of membrane aerated and perfused animal cell bioreactors by an improved medium perfusion. In: Animal Cell Culture and Production of Biologicals, Sasaki R and Ikura K (eds.), Kluwer, Dordrecht, 61-73.

Bülles J, Barziuk H, Klossom RJ, Schickle HP and Gronau S (1990) Pharmacia Application Paper, A 49 6/90.

Büntemeyer H, Bödeker BGD and Lehmann J (1987) Membrane- stirrer-reactor for bubble free aeration and perfusion. In: Modern Approaches to Animal Cell Technology, Spier RE and Griffiths JB (eds), Butterworth, London, 411-419.

Büntemeyer H, Lütkemeyer D and Lehmann J (1991) Optimization of serum-free processes for antibody production. Cytotechnology 5: $57-67$

Fenge C, Klein C, Heuer C, Siegel U and Fraune E (1993) Agitation, aeration and perfusion modules for cell culture bioreactors. Cytotechnology 11: 233-244.

Flaschel E, Wandrey C and Kula M-R (1983) Ultrafiltration for the separation of biocatalysis. In: Advances in Biochemical Engineering/Biotechnology, Fiechter A (ed), Springer, Berlin, Vol. 26: $73-142$

Meireles M (1991) Effects of protein fouling on the apparent pore size distribution of sieving membranes. Journal of Membrane Science 56: 13-28.

Le MS and Gollan KL (1989) Fouling of microporous membranes in biological applications. Journal of Membrane Science 40: 231242.

Lehmann J, Vorlop J and Büntemeyer H (1988) Bubble free reactors and their development for continuous culture with cell recycle. In: Animal Cell Biotechnology 3, Spier RE and Griffiths JB (eds), Academic Press, London, 221-237.

Address for offprints: Heino Büntemeyer, University of Bielefeld, Technical Faculty, Institute for Cell Culture Technology, P.O. Box 100131, 33501 Bielefeld, Germany.. 